\title{
OS SENTIDOS DA FORMAÇÃO: NARRATIVAS DE PROFESSORES DE INGLÊS SOBRE SUAS EXPERIÊNCIAS DE ENSINO E APRENDIZAGEM
}

\section{THE SENSES IN EDUCATION: NARRATIVES OF ENGLISH TEACHERS ABOUT THEIR TEACHING AND LEARNING EXPERIENCES}

\author{
Andréa Machado de Almeida Mattos ${ }^{1}$ \\ Érika Amâncio Caetano ${ }^{2}$ \\ Universidade Federal de Minas Gerais (UFMG)
}

\begin{abstract}
RESUMO
Este trabalho enfoca as experiências de ensino e aprendizagem de inglês de um grupo de professores que participou de um curso de especialização em ensino numa grande universidade brasileira. O objetivo do texto é apresentar e discutir narrativas de experiências vividas por esses professores relacionadas aos cinco sentidos do corpo humano: audição, visão, paladar, tato e olfato. O projeto foi inspirado em sugestão de Pennycook (2015) sobre pesquisas relacionadas aos sentidos humanos e envolve narrativas sobre ensino e aprendizagem de inglês. Os resultados mostram um conjunto de narrativas relacionadas aos sentidos humanos que podem estar associadas a questões de empoderamento, agência, pertencimento e ao desejo de ser professor de inglês. Conclui-se que formadores de professores podem criar espaços para que seus alunos e professores em formação se sintam parte de uma nova realidade e usem o poder do conhecimento da língua para conquistar seu lugar no mundo.
\end{abstract}

PALAVRAS-CHAVE: Formação de Professores. Narrativas. Sentidos do Corpo Humano.

\begin{abstract}
This paper focuses on the experiences of teaching and learning English of a group of teachers who participated in a diploma course on teaching in a large Brazilian university. The purpose of the text is to present and discuss narratives of experiences lived by these teachers related to the five human senses: hearing, sight, taste, touch and smell. The project was inspired by Pennycook's (2015) suggestion on research related to the human senses and involves narratives about teaching and learning English. The results show a set of narratives related to the human senses that may be associated to issues of empowerment, agency, belonging and the desire to become an English teacher. We conclude that teacher education can create spaces so that students and in-service teachers feel part of a new reality and use the power of language knowledge to conquer their place in the world.
\end{abstract}

KEY WORDS: Teacher Education. Narratives. Human Senses.

\footnotetext{
${ }^{1}$ Doutora em Estudos Linguísticos, Professora Adjunta da Faculdade de Letras (FALE) da UFMG e Pesquisadora Nível Pq2 do CNPq - Conselho Nacional de Desenvolvimento Científico e Tecnológico (Processo n. 312405/20170). Atualmente é Professora Residente no Instituto de Estudos Avançados Transdisciplinares (IEAT) da UFMG, em Belo Horizonte-MG. E-mail: andreamattos@ufmg.br / codigo orcid.org/0000-0003-3190-7329.

2 Doutora em Estudos Linguísticos, Professora Adjunta da Faculdade de Letras (FALE) da UFMG. E-mail: erikasoares.ingles@gmail.com / codigo orcid.org/0000-0002-5147-7728.

As autoras deste trabalho são pesquisadoras do NECLLE - Núcleo de Estudos Críticos sobre Linguagens, Letramentos e Educação, da UFMG, um grupo registrado no CNPq.
} 


\section{INTRODUÇÃO}

Recentemente, a pesquisa narrativa tem sido bastante usada na área de ensino de línguas e formação de professores de línguas com o objetivo de melhor compreender as experiências vividas por aprendizes e professores (ver, por exemplo, CASANAVE; SCHECTER, 1997; KALAJA; MENEZES; BARCELOS, 2008; MATTOS, 2009a). Esse tipo de pesquisa, especialmente na área de ensino de inglês como língua estrangeira (ILE), foi grandemente inspirada na obra de Clandinin e Connely (2000) sobre pesquisa narrativa. Connelly e Clandinin (1990) argumentam que "os seres humanos são organismos contadores de histórias que, individual e coletivamente, levam uma vida narrada" (p. 2). Assim, para esses autores, "o estudo da narrativa é o estudo das formas como os seres humanos experimentam o mundo" (p. 2). A pesquisa narrativa, então, é um processo através do qual os pesquisadores coletam informações sobre o fenômeno que querem estudar utilizando narrativas e histórias (CLANDININ et al, 2015).

Neste trabalho, apresentamos e discutimos narrativas de experiências vividas relacionadas ao ensino e à aprendizagem de inglês de um grupo de professores em serviço inseridos em um Curso de Especialização em Ensino de Inglês na Universidade Federal de Minas Gerais. Os dados para este estudo foram gerados através de uma tarefa narrativa escrita usada como atividade reflexiva final em uma das disciplinas ${ }^{4}$ do curso, ministrada em julho de 2015, pelas duas autoras deste trabalho. O curso, intitulado "Abordagens Contemporâneas para o Ensino de Inglês como Língua Estrangeira", foi concebido como um espaço para que os participantes pudessem refletir sobre suas práticas de ensino de inglês e (re)imaginar seu futuro em termos das mudanças que gostariam de ver em suas vidas, em sua profissão e em sua comunidade em geral. Para esse fim, o conteúdo da disciplina foi apresentado e desenvolvido através de atividades reflexivas colaborativas que abriram espaço para que os participantes repensassem suas crenças e seus conhecimentos na área, bem como suas atitudes e práticas pedagógicas como alunos e professores de ILE.

Para elaborar a atividade reflexiva final, buscamos inspiração no trabalho de Pennycook (2015) sobre inglês como língua internacional/Língua Franca apresentado em um minicurso no XI Congresso Brasileiro de Linguística Aplicada (XI CBLA), em Campo Grande-MS, organizado pela Universidade Estadual de Mato Grosso do Sul (UEMS) e pela Associação Brasileira de Linguística Aplicada (ALAB). Em sua apresentação sobre o tema, Pennycook afirmou que o ensino e a aprendizagem de inglês já foram pesquisados sob a perspectiva dos cinco sentidos do corpo humano, especialmente a audição (habilidade de compreensão oral) e a visão (habilidade de leitura), mas também o tato, como em pesquisas sobre aspectos mais sinestésicos da aprendizagem de línguas, e mesmo o paladar, que tem sido pesquisado nas salas de aula de aprendizagem de línguas através de aulas práticas de culinária e degustação como parte da prática dos alunos. No entanto, na opinião do pesquisador, o olfato ainda é um dos sentidos humanos que carece de pesquisas sobre aprendizagem de línguas a ele relacionadas.

Nosso objetivo, portanto, era a princípio tentar compreender melhor as experiências de ensino e/ou aprendizagem de nossos participantes para relacionar essas experiências com seu desejo ou decisão de se tornarem professores de inglês. Para isso, solicitamos aos participantes

\footnotetext{
${ }^{3}$ Tradução nossa, assim como em todas as demais citações feitas a partir de obras publicadas em língua inglesa, no restante deste trabalho.

${ }^{4} \mathrm{O}$ projeto que deu origem a este trabalho, por se tratar de pesquisa com seres humanos, foi submetido ao Comitê de Ética em Pesquisa (COEP) por meio de sua vinculação ao projeto principal intitulado "Letramentos e Ensino de Inglês como Língua Estrangeira: formando professores para a justiça social”, que tem como investigadora principal a Professora Dra. Andréa Machado de Almeida Mattos, e obteve aprovação em 19/05/2015, sob o número CAAE 420990315.5.0000.5149. Uma versão anterior deste texto foi publicada em inglês no e-book OLIVEIRA, A. L. A. M.; BRAGA, J. C. F. (Orgs.). Inspiring insights from an English teaching scene. Belo Horizonte: FALE/UFMG, 2017. p. 26-43. Agradecemos aos dois revisores anônimos pelos comentários e revisões solicitadas, que muito contribuíram para a melhoria da qualidade desta versão.
} 
que refletissem sobre suas experiências passadas de aprendizagem e de ensino de línguas e que contassem as histórias dessas experiências em relação aos seus sentidos: audição, visão, paladar, tato e olfato. Assim, cada participante escreveu uma narrativa reflexiva em inglês relatando alguma experiência de ensino ou de aprendizagem de inglês que estivesse relacionada a um ou mais dos cinco sentidos humanos. O resultado foi um conjunto incrível de narrativas pessoais que relacionam diversos aspectos da aprendizagem e do ensino de línguas aos sentidos do corpo humano. Por meio dessas narrativas, foi possível perceber como a aprendizagem de línguas e, por consequência, o ensino de línguas, podem ser afetados pelos nossos sentidos e as várias maneiras pelas quais entramos em contato com a língua estrangeira, seus falantes nativos e nossos professores de línguas em nossas experiências diárias.

Aqui, abordaremos primeiramente o conceito de narrativas e de pesquisa narrativa, focando em como esses conceitos têm sido utilizados na pesquisa sobre ensino e aprendizagem de língua estrangeira em geral e, especificamente, no Brasil, e principalmente no ensino e aprendizagem de inglês e na formação de professores. Depois, apresentaremos e discutiremos algumas das narrativas geradas neste estudo. Primeiro, realizaremos uma análise numérica das narrativas, contando-as e categorizando-as em relação aos cinco sentidos do corpo humano: audição, visão, paladar, tato e olfato. Também apresentaremos uma análise qualitativa que revelou os significados que os participantes atribuíram a suas narrativas.

A pesquisa narrativa, de cunho qualitativo por natureza, tem como objetivo a compreensão dos significados das "palavras como dados" (PINNEGAR; DAYNES, 2007, p. 15). Nesse sentido, as palavras narradas pelos participantes desta pesquisa levaram a duas formas de interpretação dos dados. Por meio da análise qualitativa realizada neste estudo, foi possível perceber as influências dos sentidos do corpo humano em relação às decisões dos participantes para se tornarem professores de inglês, o que era nosso objetivo principal. Além disso, saltou-nos aos olhos também, embora não tenha sido um dos objetivos iniciais da pesquisa, o poder das experiências narradas como fator de empoderamento dos participantes em várias esferas de suas vidas. Esses dois conjuntos de narrativas, assim, são apresentados e discutidos nas seções de análise dos dados. $\mathrm{Na}$ seção final, argumentamos que narrativas e histórias de ensino e aprendizagem, por mais parciais que sejam, podem vislumbrar experiências de empoderamento, agência, participação e pertencimento dos participantes, bem como seus desejos de se tornarem professores de línguas, conforme revelado pelos dados gerados nesta pesquisa.

\section{Narrativas no ensino de línguas e na formação de professores}

Narrativas têm sido entendidas como histórias, mitos, dramas e relatos históricos que focalizam a intenção e a ação humanas e, segundo Bruner (1986), são "compostos por uma sequência única de eventos, estados mentais, acontecimentos envolvendo seres humanos como personagens ou atores" (p. 43). De acordo com Bruner (2002), ouvimos narrativas e histórias "infinitamente, [...] e [estas] parecem quase tão naturais quanto a própria linguagem" (p. 3). Para ele, as narrativas e histórias são parte de nossas vidas desde a mais tenra idade e nosso relacionamento com elas continua para sempre, ao ponto de as narrativas e histórias se tornarem uma forma de pensar, uma forma de organizar e compreender nossas próprias experiências e as experiências de outras pessoas. Bruner afirma que os seres humanos têm uma extraordinária "capacidade de organizar e comunicar a experiência de forma narrativa" (p. 16) e é isso que torna possível a nossa vida coletiva. O autor também acredita que, ao contar e ouvir narrativas e histórias, incluindo nossas próprias histórias, construímos uma imagem de nós mesmos e gradualmente nos tornamos quem somos. Na visão de Bruner, narrativas e histórias não só relatam fatos e realidade, mas também constroem a realidade e, ao fazê-lo, essas narrativas e histórias moldam nossa experiência no mundo. Como diz o autor, "construímos e reconstruímos [nossas identidades] constantemente para atender às necessidades das situações que encontramos, 
e fazemos isso com a orientação de nossas memórias do passado e nossas esperanças e medos para o futuro" (BRUNER, 2002, p. 64).

Acreditamos que essa constante construção e reconstrução de nós mesmos por meio da narração de histórias também acontece na vida profissional, isto é, na construção da identidade profissional. Além disso, da mesma forma que as histórias em nossas memórias têm um papel importante na construção de nós mesmos, essas histórias também têm um papel relevante na construção e reconstrução de nossas identidades profissionais. Com efeito, em um estudo narrativo realizado com professores em formação, Mattos (2009b) discute as histórias de esperança e desesperança dos participantes para se tornarem professores de inglês. Os resultados desse estudo mostram que muitas histórias dos participantes se referem a suas experiências anteriores como aprendizes de inglês. Em muitos casos, como o estudo relata, os participantes tiveram suas esperanças de se tornarem professores de inglês aumentadas - ou às vezes diminuídas - por suas boas ou más experiências anteriores de aprendizagem de língua.

Barcelos (2008) concorda que "as narrativas são um excelente método para capturar a essência da experiência humana e [também] da aprendizagem e da mudança" e acrescenta que "as narrativas mostram as maneiras únicas com que cada pessoa lida com seus dilemas e desafios" (p. 37). A autora define a experiência como "o modo humano de estar no mundo" (p. 37). Para ela, "tudo o que experimentamos leva algo do passado e modifica a qualidade das experiências futuras" (2008, p. 37). Esse ponto de vista aponta para a possibilidade de que as experiências passadas dos professores de inglês possam influenciar sua atuação em sala de aula, o que é foco deste trabalho.

Como vemos, tanto a pesquisa quanto as perspectivas narrativas (CASANAVE; SCHECTER, 1997; CLANDININ; CONNELLY, 2000) sobre o ensino e a formação de professores abriram espaço para se estudar as escolhas e as vozes dos professores, ajudando tanto os pesquisadores quanto os professores a entenderem melhor a natureza altamente contextual da atividade docente (FREEMAN, 1996). Blake e Haines (2009) defendem o "uso de narrativas como meio de compreensão do processo de ensino" (p. 47) e, quando se trata da atividade docente, é importante ressaltar que as narrativas fornecem aos pesquisadores não apenas um amplo alcance relativo à prática de professores per se, mas também informações relevantes sobre os pontos de vista, as necessidades e especificidades dos alunos.

Kalaja, Menezes e Barcelos (2008) reúnem, em uma coleção editada, trabalhos de vários autores que também enfatizam o poder das narrativas na pesquisa sobre ensino e aprendizagem de línguas e destacam "as inúmeras maneiras pelas quais as narrativas podem lançar luz sobre diferentes questões de ensino e aprendizagem de línguas e desenvolvimento profissional" (p. 224). Esses autores descrevem a narrativa "como uma ferramenta que permite a compreensão do impacto de nossas experiências, a revelação de ideias profundamente escondidas e a oportunidade de entender a mudança nas pessoas e nos eventos" (p. 224).

Embora possa parecer difícil "pensar narrativamente" devido ao fato de que "o foco em metas, resultados e recursos informa as políticas e práticas institucionais que moldam as paisagens de conhecimento [do pesquisador]" (CLANDININ; CONNELY, 2000, p. 25), os estudos narrativos mostram que podem oferecer insights inspiradores sobre a prática de ensino de línguas a partir da perspectiva do próprio professor. Mattos (2009c) mostra como um estudo narrativo realizado com um professor de línguas em seu próprio ambiente profissional pode retratar aspectos cruciais para a compreensão de uma sala de aula de LE como um complexo sistema de fatores, que vão desde o contexto de aprendizagem até pressões internas e externas. Tais fatores, bem como a compreensão de sua especificidade, somente puderam ser identificados devido à abordagem subjetiva e contextualmente sensível da pesquisa narrativa. De acordo com Paiva (2005), "as narrativas de aprendizagem revelam que as histórias não se repetem, porque, embora várias delas relatem desejos e queixas similares, seus autores reagem de forma diferente e outros fatores também interferem nas suas experiências" (s. p.), o que evidencia a complexidade dos processos de aprendizagem de línguas. 
Assim, é possível inferir que os estudos narrativos proporcionam aos professores não só oportunidades para entender sua própria prática e seu contexto, mas também para identificar interseções dentro da área como um todo. Uma vez que eles têm a chance de comparar e contrastar sua própria experiência com o trabalho de outros profissionais, é possível que eles abordem questões anteriormente não consideradas e construam o conhecimento de forma colaborativa.

Por meio do trabalho desenvolvido nesse campo, é possível observar aspectos relativos à prática de ensino de línguas como um todo e perceber questões importantes relacionadas à aprendizagem de línguas dos professores, o que pode, até certo ponto, explicar alguns aspectos relacionados a sua prática de ensino. Paiva (2006), por exemplo, concentra-se nas narrativas dos professores sobre suas experiências de aprendizagem de línguas e suas memórias recentes. Ao longo de seu trabalho, é possível notar que os participantes tendem a comparar suas vidas como estudantes com as experiências de seus alunos atuais na escola. Ao usar seu próprio processo de aprendizagem de línguas como ferramenta, os entrevistados na pesquisa de Paiva ou se sentiram motivados a desenvolver as habilidades e o envolvimento dos alunos na disciplina ou optaram por reproduzir um modelo de desesperança e insatisfação em suas salas de aula.

Considerando que as experiências anteriores dos professores de línguas enquanto alunos podem ser associadas à sua vida atual como professores (BAILEY et al, 1996; MATTOS, 2014), pode-se supor que tais experiências podem eventualmente influenciar seu desejo de seguir carreira no ensino de línguas. Dito isso, o presente estudo teve como objetivo principal analisar as experiências de ensino e aprendizagem de ILE dos participantes de um curso de especialização relacionadas aos cinco sentidos do corpo humano, a fim de identificar possíveis conexões entre essas experiências e sua decisão de se tornarem professores de inglês. No entanto, as narrativas geradas para este estudo também revelaram que as experiências dos participantes relacionadas aos seus sentidos levaram ao seu empoderamento pessoal enquanto aprendizes e usuários da língua inglesa. Esses dois pontos serão discutidos nas seções que se seguem.

\section{Os sentidos nas narrativas: tornando-se professores de inglês}

Conforme mencionado na introdução deste texto, Pennycook (2015) afirmou que várias pesquisas sobre o ensino e a aprendizagem de inglês já abordam o tema dos cinco sentidos do corpo humano, como, por exemplo, a audição (KRASHEN et al, 2018; ROST, 2001; SIEGEL, 2018; VANDERGRIFT; CROSS, 2018; dentre outros) e a visão (AHMED; HAN, 2018; GRELLET, 1995; JACOBS; SHEGAR, 2018; NUTTAL, 2000; SADEGHI, 2018; WALLACE, 2001; para citar apenas alguns). Pesquisas envolvendo os sentidos da audição e da visão, como é possível notar, são encontradas na área de ILE em quantidade bastante expressiva, já que envolvem duas habilidades básicas do uso da língua - a compreensão oral e a leitura, respectivamente. Embora em menor escala, outros sentidos humanos, como ressaltou Pennycook (2015), também já foram pesquisados. Com relação ao sentido do tato, podemos citar pesquisas e trabalhos sobre aspectos mais sinestésicos da aprendizagem de línguas, como o ensino de vocabulário por meio de atividades lúdicas que envolvem esse e outros sentidos (ver, por exemplo, AJAYI, 2018; HELLMAN, 2018). E até mesmo o paladar tem sido pesquisado nas salas de aula de aprendizagem de línguas por meio de aulas práticas de culinária e degustação como parte da prática dos alunos (ver, nesse caso, FELDER; HENRIQUES, 1995; PRESTON et al, 2015). No entanto, na opinião do pesquisador, o olfato ainda é um dos sentidos humanos que carece de pesquisas sobre aprendizagem de línguas a ele relacionadas. A pesquisa aqui relatada, assim, buscou relacionar os sentidos do corpo humano com as experiências de aprendizagem de línguas dos participantes.

Como já foi explicado, ao final do curso, os participantes, isto é, os professores em formação continuada, escreveram uma narrativa final em inglês, já que o curso de especialização era exclusivo para professores de inglês. A atividade reflexiva final, como nós a chamamos, 
solicitava que os alunos produzissem uma narrativa escrita que de algum modo englobasse um dos cinco sentidos relacionados às suas experiências anteriores de aprendizagem e/ou de ensino de inglês, ou seja, as narrativas deveriam estar relacionadas à sua vida em "inglês". É importante esclarecer que não foi exigido nenhum conteúdo específico que as narrativas deveriam apresentar além de relacionar as atividades em inglês e os cinco sentidos do corpo humano. Em outras palavras, a princípio foi informado aos alunos apenas que o foco de nossa análise seriam suas experiências em relação aos sentidos do corpo humano e o nível de reflexividade que as narrativas escritas apresentassem, sem que fosse necessário escrever sobre algum assunto específico que tivesse sido tratado durante o curso. Por outro lado, era esperado que tais narrativas trouxessem naturalmente reflexões relacionadas ao conteúdo explorado durante o curso, já que os participantes estavam encerrando um intenso curso de especialização sobre ensino e aprendizagem de língua - foco também das narrativas - e haviam feito várias leituras recentes sobre o assunto. Ao iniciarmos a análise das narrativas, percebemos que grande parte delas relatava experiências que poderiam ter contribuído para o empoderamento pessoal do participante ou para sua eventual escolha pela carreira docente e, por isso, este se tornou o foco deste trabalho.

Quarenta e sete participantes do curso contribuíram com suas narrativas escritas, sendo que onze participantes escreveram sobre suas experiências como professores, e não como alunos. Essas onze narrativas foram descartadas e não foram analisadas para os propósitos deste texto, já que aqui nosso foco são as experiências passadas de aprendizagem que poderiam ter influenciado os participantes a se tornarem professores de línguas. Os outros trinta e seis participantes escreveram sobre suas experiências como alunos de línguas. Também deve ser mencionado que quatro participantes associaram a ideia de "toque" (tato) com uma experiência metaforicamente tocante ou inspiradora. Por exemplo, três alunas mencionaram que foram "tocadas" ou inspiradas por seus professores anteriores, e outra aluna mencionou ter "tocado", no sentido de inspirar, seus alunos a partir do estabelecimento de relações entre a sala de aula e a realidade de cada um. Um participante mencionou sua insatisfação com a carreira docente e não fez nenhuma conexão de suas experiências com os sentidos humanos, como era a proposta da atividade. Essas cinco narrativas também foram descartadas.

Dessa forma, 31 narrativas geradas pelos participantes no curso foram analisadas e categorizadas de acordo com os propósitos deste estudo. A tabela abaixo mostra os resultados da análise numérica das narrativas dos participantes como alunos de inglês associados aos seus sentidos, suas vidas como estudantes e as possíveis conexões entre essas experiências e seu consequente desejo de se tornarem professores de inglês.

Tabela - Narrativas dos participantes relacionadas aos sentidos

\begin{tabular}{|c|c|c|}
\hline SENTIDO & $\begin{array}{c}\text { Número de } \\
\text { narrativas } \\
\text { (total: } 31)\end{array}$ & DETALHES \\
\hline Audição & 13 & $\begin{array}{ll}\text { - } & \text { Ouvir música (6) } \\
\text { - } & \text { Ouvir conselhos das pessoas (2) } \\
\text { - } & \text { Imitar os personagens do livro depois de ouvi-los (1) } \\
\text { - } & \text { Experiência no exterior: pronúncia diferente (3) } \\
\text { - } & \text { Ouvir parentes que falam inglês em casa (1) }\end{array}$ \\
\hline Visão & 11 & $\begin{array}{ll}\text { - } & \text { Desempenho teatral (2) } \\
\text { - } & \text { Autorretrato: Empoderamento (3) } \\
\text { - } & \text { Estágio: vídeos produzidos por alunos (1) } \\
\text { - } & \text { Viagem de campo do clube de livros para Salem (1) } \\
\text { - } & \text { Cartas para parentes no exterior (1) } \\
\text { - } & \text { Desenhos animados (1) } \\
\text { - } & \text { Aulas coloridas (1) }\end{array}$ \\
\hline
\end{tabular}




\begin{tabular}{|c|c|c|}
\hline & & - $\quad$ Estudante de intercâmbio australiana (1) \\
\hline Paladar & 3 & $\begin{array}{l}\text { - } \text { Café da manhã canadense (1) } \\
\text { - Bolo e café na casa da professora particular: senso de } \\
\text { pertencimento (1) } \\
\text { - Gosto do conhecimento (1) }\end{array}$ \\
\hline Olfato & 3 & $\begin{array}{ll} & \text { Aulas na cozinha: cheiro de biscoitos (1) } \\
\text { - } & \text { Perfume especial da sala de aula (1) } \\
\text { - } & \text { Livros antigos sobre educação (1) }\end{array}$ \\
\hline Tato & 1 & - $\quad$ Aula de culinária: preparação de alimentos (1) \\
\hline
\end{tabular}

Os resultados dessa categorização retratam a diversidade das narrativas geradas neste estudo. Essa categorização, embora puramente numérica, permite perceber que alguns sentidos parecem predominar nas narrativas dos participantes, quais sejam os sentidos da audição e da visão. Isso pode ser explicado, como já dissemos acima, pelo fato de esses sentidos estarem diretamente relacionados às habilidades de compreensão oral e de leitura, que são uma das quatro habilidades principais no processo de aprendizagem de uma língua estrangeira, juntamente com a produção oral e escrita.

Uma análise mais profunda e qualitativa das narrativas também foi realizada, focalizando o conteúdo dos relatos. Essa parte da análise foi dividida em duas seções: Os Sentidos do Empoderamento, onde discutimos os relatos que abordam a relação entre aprendizagem de inglês e empoderamento; e Tornando-se Professores de Inglês, que abrange as experiências de aprendizagem dos participantes como uma ferramenta de motivação para seguir seu caminho na carreira de professor. Esses dois tipos de experiências serão discutidos mais profundamente nas seções a seguir.

\subsection{Os sentidos do empoderamento}

Entre as muitas experiências representadas nas narrativas, foi possível observar que várias delas falavam sobre como as experiências dos participantes relacionadas aos seus sentidos levaram ao seu empoderamento pessoal. Quanto à audição, por exemplo, as narrativas envolvendo experiências no exterior e até mesmo a escuta de músicas mostram que a possibilidade de compreender o inglês permitiu que os participantes vivenciassem outra cultura e se sentissem parte do ambiente da língua inglesa. $\mathrm{O}$ exemplo a seguir mostra o empoderamento pessoal por meio da compreensão auditiva da língua inglesa e a produção de novos enunciados:

My experience as an English learner started in a very early age, I think I can almost say that ever since I can remember my ears were used [to] the sound of English. That's because my grandmother was an English teacher, and my mom had also taught English when she was younger. I am not sure exactly when I started to figure out that the language that she was speaking with her students [was] English. But I do remember that I was very curious to understand this

\footnotetext{
5 Os excertos das narrativas não foram editados. No entanto, pequenas alterações foram inseridas pelas pesquisadoras entre colchetes [] para facilitar a compreensão. Como as narrativas foram escritas originalmente em inglês, optamos por traduzi-las em pé de página:

Minha experiência como aprendiz de inglês começou em uma idade muito precoce, acho que quase posso dizer que, desde que me lembro, meus ouvidos foram acostumados ao som do inglês. Isso porque minha avó era professora de inglês e minha mãe também havia ensinado inglês quando era mais nova. Eu não tenho certeza de quando exatamente eu comecei a descobrir que a língua que ela estava falando com seus alunos [era] inglês. Mas eu lembro que eu ficava muito curiosa para entender esse som diferente que meus ouvidos ouviam. Então, quando fiquei um pouco mais velha, comecei a criar palavras para me comunicar com minha avó e com minha mãe. [Um] exemplo de uma dessas palavras que eu criei como uma criança que deseja falar inglês é a palavra: "kisão". Eu queria dizer beijo grande, então na minha mente eu só precisava adicionar o sufixo "ão” à palavra beijo. Minha mãe não me corrigiu no momento e eu continuei falando assim e criando outras palavras e tinha certeza de que estava falando inglês!
} 
different sound that my ears [were] listening to. So when I was a little older I started to create words to communicate with my grandmother and with my mom. [An] example of one of these words that I crated as a child who desired to speak English, is the word: "kisão". I wanted to say big kiss, so in my mind I had just to add the suffix “ão" to the word kiss. My mom didn't correct me at the time and I kept speaking like this and creating other words and I was sure that I was speaking English!

Podemos ver, nesse excerto, que a participante se sentiu envolvida com o idioma, de modo que sua curiosidade levou ao desejo de aprender a língua inglesa para se comunicar com sua avó e sua mãe. Ao observar a linguagem falada ao redor dela, a participante começou a produzir seus próprios chunks ou pedaços de linguagem, buscando se sentir parte desse cenário particular. É interessante notar que, embora os enunciados produzidos não fossem exatamente precisos, eram suficientes para que a participante se fizesse entender e penetrasse esse novo ambiente, dando-lhe um senso de pertencimento, como também mostra o seguinte trecho da mesma narrativa:

Even now as an adult and an English speaker, I still say "kisão" to my mom when I want to mean big kiss. It became our own language. ${ }^{6}$

Da mesma forma, as narrativas envolvendo a visão também apontaram o sentimento de empoderamento dos participantes devido ao conhecimento de inglês. Outro excerto da narrativa anterior sobre a audição também contém um comentário sobre a experiência visual da participante em relação à linguagem. A participante mencionou que estava ansiosa para completar onze anos e ter aulas de inglês na escola. Foi quando ela teve o primeiro contato com palavras em inglês, como ela ressalta:

And when I was that age (11), I started to not just listen to those different words for me, but also to see them printed on a paper. It was heaven for me. I could not just listen but write in English! "Oh, how much I desired that my grandmother could see me, she would be very proud!", I used to think. ${ }^{7}$

Aqui podemos notar mais uma vez o papel que a aprendizagem de inglês desempenhou na vida da participante, tanto academicamente quanto pessoalmente. Quando ela menciona que sua avó teria ficado orgulhosa dela, é possível inferir que aprender essa língua era motivo de orgulho e autoempoderamento, uma vez que ela poderia usar a língua alvo em mais de uma habilidade.

Ainda na mesma narrativa, foi possível encontrar mais um exemplo envolvendo visão e aprendizagem de inglês. A participante explica que, quando estava na universidade, conheceu um grupo de estudantes americanos que a ajudaram a alcançar o sonho de visitar um país de língua inglesa pela primeira vez. O excerto a seguir contém evidências em relação ao seu sentimento de empoderamento pela experiência de aprender inglês:

They [the American students] left Brazil and 6 months later I realized my dream that I had since I was a child: I saw with my own eyes that magical land that I have always heard about. I was in the USA! I spent 4 months there and it was

\footnotetext{
${ }^{6}$ Mesmo agora como adulta e falante do inglês, eu ainda falo "kisão" para minha mãe quando quero dizer beijo grande. Tornou-se a nossa língua.

${ }^{7}$ E quando eu tinha essa idade (11), comecei não apenas a ouvir essas palavras diferentes para mim, mas também a vê-las impressas em um papel. Foi o paraíso para mim. Eu podia não apenas ouvir, mas escrever em inglês! "Ah, como eu desejei que minha avó pudesse me ver, ela ficaria muito orgulhosa!", eu costumava pensar.
} 
for sure the best months for me. I got to experience everything that I have just seen in the movies. It was unique! ${ }^{8}$

A possibilidade de viver em contato com uma cultura é claramente uma experiência significativa quando se trata de aprender uma nova língua, como pudemos ver no excerto acima. É importante mencionar, no entanto, que tal experiência não implica necessariamente viajar para o exterior. A exemplo do que vem sendo chamado de "internacionalização em casa" (GONÇALVES, 2009; MAUÉS; BASTOS, 2017; RAMOS, 2018), uma das participantes mencionou sua experiência ao hospedar uma estudante de intercâmbio da Austrália. A partir dessa narrativa relacionada à visão, é possível observar que o contato com um falante nativo representou, para essa participante, uma oportunidade de cruzar fronteiras e estar em contato com outra cultura que era completamente diferente da sua, como nós podemos ver no seguinte trecho:

A few days later she arrived. Her name was Sam, she came from Australia and she looked like nothing I'd ever seen. She was extremely pale, had blue eyes and thin, baby like, white blond hair. She was quite overweight but still exuded selfconfidence, which is a rare thing in a sixteen-year-old. She had dyed half her white hair black, had a huge nose ring and lots, lots, lots of acne. Needless to say I was fascinated. ${ }^{9}$

A mesma participante acrescenta que, devido a suas habilidades de audição, ela pode ficar sabendo de uma grande quantidade de informações sobre as experiências da menina:

She was actually pretty cool and, although her looks stood out to me the most, I still could manage to attentively hear her stories being told in her strong "Aussie" accent. Turns out she was a bit of a problem child back home. She had left Australia because she [was] being bullied for having slept with half her high school. We also learned that ours was her third home in Brazil because she had been expelled from the previous two. ${ }^{10}$

No final da narrativa, a participante menciona que continua sendo amiga de sua hóspede australiana e ilustra seu autoempoderamento ao expressar como sua grande habilidade de compreensão oral na língua inglesa a aproximou do ambiente cultural da língua-alvo:

\footnotetext{
${ }^{8}$ Eles [os estudantes americanos] deixaram o Brasil e 6 meses depois eu realizei meu sonho que eu tinha desde que eu era criança: eu vi com meus próprios olhos aquela terra mágica de que sempre ouvi falar. Eu estava nos EUA! Passei 4 meses lá e foram com certeza os melhores meses para mim. Eu pude experimentar tudo o que eu somente tinha visto nos filmes. Foi único!

9 Poucos dias depois ela chegou. O nome dela era Sam, ela vinha da Austrália e não parecia com nada que eu já tinha visto. Ela era extremamente pálida, tinha olhos azuis e cabelos loiros brancos e finos como os de um bebê. Ela estava com excesso de peso, mas ainda exalava autoconfiança, o que é uma coisa rara em pessoas de dezesseis anos. Ela tinha tingido de preto a metade do cabelo branco, tinha um enorme piercing no nariz e muita, muita, muita acne. Desnecessário dizer que fiquei fascinada.

${ }^{10} \mathrm{Na}$ verdade ela era muito legal e, embora sua aparência fosse o que mais me chamava atenção, eu ainda conseguia ouvir atentamente suas histórias contadas em seu forte sotaque "australiano". Acontece que ela era uma criança problema em sua casa. Ela tinha deixado a Austrália porque ela [estava] sofrendo bullying por ter dormido com a metade de sua escola de ensino médio. Nós também ficamos sabendo que a nossa era a terceira casa dela no Brasil porque ela havia sido expulsa das duas anteriores.
} 
To this day we're friends on Facebook and every now and then, speak on Skype. She still compliments me on my hearing and tells me I can mimic her accent almost perfectly. I learned a lot from her. ${ }^{11}$

Da mesma forma que interagir com falantes nativos e visitar países de língua inglesa podem contribuir para o sentido de conquista e empoderamento, aprender uma nova língua também pode levar as pessoas a se verem de forma diferente. Uma das narrativas oferece uma perspectiva intrigante sobre esse tema. De acordo com o participante, ele sofreu bullying na escola e saber inglês representou para ele a oportunidade de se dar bem com seus colegas de classe e se ver como uma pessoa melhor:

Thus, as soon as I started opening some room in my life for the English language, my classmates began to understand how good I was at it, and how able I was at helping them with their English exercises and tests at school. The moment I noticed I could help those who used to bully me, and make me feel uncomfortable about myself, in that sense, be the better person, I started to invest my time and efforts to learn the language further and further. ${ }^{12}$

Pode-se inferir a partir desse excerto que a conscientização do participante sobre seu empoderamento ao enfrentar a situação influenciou seu desejo de continuar aprendendo a língua e, eventualmente, abraçar a carreira docente, como discutimos abaixo. O que é relevante mostrar neste momento é outro excerto que mostra o senso de pertencimento e também o novo senso de si mesmo que este participante experimentou depois de aprender a língua inglesa. Para falar desse senso de si mesmo, o participante usa uma expressão específica que pode ser tomada como uma referência a Adichie (2009), um dos vídeos usados durante o curso para fomentar a reflexão dos participantes, conforme mostrado abaixo:

At the age of seventeen, I had a very good proficiency level of English, if compared to my fellow classmates. I could already speak very well, and translate songs to my friends by ear. I was still different. However, now, special too. I started regaining a sense of self. ${ }^{13}$

Nesse excerto específico, entendemos que a visão foi associada não apenas a experiências concretas de ver outro país ou pessoa que pertencia a uma cultura diferente, mas também visões fascinantes de si e de outras pessoas como agentes de sua própria auto aceitação, poder e desejo de continuar aprendendo.

Em outra narrativa associando essa perspectiva subjetiva da visão com realização pessoal, a participante observa que sua experiência em inglês envolveu a troca de cartas com parentes que vivem no exterior:

11 Até hoje somos amigas no Facebook e de vez em quando, falamos no Skype. Ela ainda me elogia pela minha habilidade de compreensão oral e me diz que posso imitar seu sotaque quase que perfeitamente. Eu aprendi muito com ela.

12 Então, assim que comecei a abrir algum espaço na minha vida para a língua inglesa, meus colegas de turma começaram a entender como eu era bom nisso e como eu conseguia ajudá-los com seus exercícios e testes de inglês na escola. No momento em que notei que eu poderia ajudar aqueles que costumavam me fazer bullying e me sentir desconfortável com relação a mim mesmo, nesse sentido, ser a pessoa melhor, comecei a investir meu tempo e esforços para aprender mais e mais a língua.

${ }^{13}$ Com dezessete anos, eu tinha um nível de proficiência muito bom em inglês, se comparado aos meus colegas de classe. Eu já podia falar muito bem e traduzir músicas para meus amigos de ouvido. Eu ainda era diferente. No entanto, agora, também especial. Comecei a recuperar um senso de mim mesmo. 
My experience in English learning is deeply related to family. I was brought up writing letters to relatives who were living abroad and at an early age, I [was] used to the universe of English. ${ }^{14}$

Compreende-se a partir desse excerto que saber o idioma permitiu à participante trocar mais do que palavras - ela pode ter acesso a uma cultura diferente e à informação de sua família, o que mais tarde despertou seu desejo de continuar seus estudos e também seu fascínio com o idioma e tudo a ele relacionado.

Quanto ao sentido do paladar, há uma narrativa intrigante que relaciona o gosto e o cheiro de comida com um sentimento de pertencimento. Na narrativa, que ilustra como uma aula de inglês pode trazer oportunidades para ensinar muito mais do que a língua em si, a participante se refere a uma aula de culinária em que ela e seus colegas ajudaram a professora a preparar um prato tradicional brasileiro. Segundo ela, a experiência foi bastante notável no sentido de usar o inglês para realizar uma atividade prática e integrada:

I will never forget that experience, we touched on the food, prepared, the teacher took that to the stove in the snack bar of the institute, twenty minutes later cuscus was great, the whole class about ten students ate, and we could feel the smell of fresh food and also the process of preparation was seen by the students. ${ }^{15}$

Em sua narrativa, esta participante também faz uma referência explícita a um texto usado durante o curso quando menciona as brechas do contexto, um assunto que havíamos debatido em sala de aula por meio do texto de Duboc (2013). A participante considera que a atividade também envolveu desenvolvimento cultural e transformação social, uma vez que, do seu ponto de vista, valorizou sua própria cultura:

Now, thinking about remarkable situations involving some senses that specific fact came [to] my mind but also the understanding for the reason [the] teacher was doing that activity with us, not just teaching English, she was helping us to give values to our culture, to know how to talk about our particularities, she was teaching through the cracks she found in the context that we were in. ${ }^{16}$

A mesma ideia relacionada a um sentimento de pertencimento é ilustrada em uma das narrativas envolvendo o olfato. Juntamente com o toque, a narrativa seguinte trouxe uma visão clara sobre o empoderamento por meio do toque e do cheiro de artefatos de um país diferente encontrados na casa do professor de inglês da participante:

I remember, though, using several literature books that came straight from England, where her son used to live. I was amazed by the realization I was touching and smelling something that had actually come from another country - in fact, her house smelled foreign, given the many different English tea essences in her kitchen and the slight smell of mold that came from her

\footnotetext{
14 Minha experiência na aprendizagem de inglês está profundamente relacionada à família. Fui criada escrevendo cartas para parentes que viviam no exterior e, em uma idade precoce, eu estava acostumada com o universo do inglês.

15 Nunca vou esquecer essa experiência, tocamos a comida, preparamos, a professora levou para o fogão na lanchonete do instituto, vinte minutos depois cuscuz estava ótimo, toda a classe com cerca de dez alunos comeu, e podíamos sentir a cheiro de comida fresca e também o processo de preparação foi visto pelos alunos.

${ }_{16}$ Agora, pensando em situações notáveis envolvendo alguns sentidos aquele fato específico veio [à] minha mente, mas também a compreensão pelo motivo de [a] professora estar fazendo aquela atividade conosco, e não apenas ensinando inglês, ela estava nos ajudando a dar valor à nossa cultura, para saber como falar sobre nossas particularidades, ela estava ensinando através das brechas que ela encontrou no contexto em que estávamos.
} 
bookshelf. Every day I anticipated the moment to get my bicycle, go to her house and get to touch those amazing books. ${ }^{17}$

Outra narrativa sobre o sentido do paladar também retrata algumas informações relevantes sobre o empoderamento pessoal através da agência e da participação. A participante se refere a um brunch canadense que lhe foi oferecido quando morava no Canadá e, depois de descrever a comida, as bebidas e todo o cenário, ela termina por reconhecer o papel dessa experiência ao se ver como alguém que realmente pertencia àquele lugar:

I didn't eat almost anything for the rest of the day but I felt myself very Canadian and I just loved the experience. ${ }^{18}$

Para concluir esta seção, apresentamos uma narrativa que relaciona aprendizagem de inglês e empoderamento e engloba todos os sentidos para afirmar uma questão específica: aprender uma língua estrangeira - especialmente o inglês, considerando seu status como língua franca - pode contribuir para o empoderamento pessoal, autoexpressão e luta pela justiça social por parte dos envolvidos, outro assunto que havia sido debatido durante o curso, por meio do texto de Mattos (2014):

In conclusion, some people aim to learn the necessary skills to communicate through English so to get better jobs, travel around the world, understand their favorite English-speaking artists and celebrities, others to overcome social issues, to take a stand and leave a mark on the world. It does not matter the reason why one wants to learn the language, what matters is that language gives people power to defend and express themselves. Thus, if we want a more just society, we must let people speak their souls out, be freer, and at the same time, understand and celebrate our differences. Otherwise, there will still be kids at school in pain and sorrow, only because they feel, or are told, they are different. ${ }^{19}$

Esta seção, como pretendíamos, apresentou narrativas em que é possível notar uma relação entre as experiências anteriores dos participantes sobre ensino e aprendizagem de inglês com um sentimento de empoderamento de várias formas. A próxima seção da análise mostrará como algumas narrativas reuniram experiências de aprendizagem, os sentidos humanos e a escolha pela carreira de professor de inglês.

\subsection{Tornando-se professores de inglês}

A segunda parte da análise qualitativa das narrativas, também baseada no conteúdo dos relatos, mostra as experiências dos participantes envolvendo os cinco sentidos associados a seus

\footnotetext{
17 Lembro-me, porém, de usar vários livros de literatura que vieram diretamente da Inglaterra, onde seu filho costumava viver. Fiquei impressionada com a percepção de que eu estava tocando e cheirando algo que realmente veio de outro país - na verdade, sua casa cheirava a estrangeiro, devido às muitas essências de diferentes chás ingleses em sua cozinha e o leve cheiro de mofo que vinha da estante de livros. Todos os dias eu ansiava pelo momento de pegar minha bicicleta, ir até a casa dela e tocar aqueles livros incríveis.

${ }_{18}$ Eu não comi quase nada no resto do dia, mas eu me senti muito canadense e eu simplesmente adorei a experiência. ${ }_{19}$ Em conclusão, algumas pessoas pretendem aprender as habilidades necessárias para se comunicar através do inglês, para obter melhores empregos, viajar ao redor do mundo, entender seus artistas e celebridades favoritas da língua inglesa, outros para superar questões sociais, tomar uma posição e deixar uma marca no mundo. Não importa o motivo pelo qual alguém quer aprender o idioma, o que importa é que a linguagem dá poder às pessoas para se defender e se expressar. Assim, se queremos uma sociedade mais justa, devemos deixar as pessoas falarem suas almas, ser mais livres e, ao mesmo tempo, entender e celebrar nossas diferenças. Caso contrário, ainda haverá crianças na escola com dor e tristeza, apenas porque sentem, ou são ditas, que são diferentes.
} 
desejos de se tornarem professores de inglês. As narrativas envolvendo paladar, toque e olfato não indicaram especificamente qualquer relação entre tais experiências e a decisão dos participantes de se tornarem professores de inglês, provavelmente, como já apontado, porque esses sentidos não estão diretamente relacionados a habilidades de aprendizagem ou uso da língua alvo. Por essa razão, decidimos analisar apenas as narrativas envolvendo exclusivamente audição e visão.

Em primeiro lugar, vamos considerar as narrativas relacionadas à audição. Dois participantes mencionaram em suas histórias que se tornaram professores porque ouviram o conselho de alguém para fazê-lo. Em uma delas, é possível identificar que aprender o idioma representou uma oportunidade para ampliar os horizontes e alcançar o sucesso profissional:

When I was a kid, I decided to be an English teacher. My mother was a babysitter and she traveled all over the world, despite her not understanding that language very well, she would always [say]: "English is very important and if you want to have a good job, you must know it." I had become aware of the importance of [the] English language, and due to that, I started studying English at [a well-known] Institute in another city. ${ }^{20}$

Podemos observar por meio do excerto acima que o conselho da mãe foi a principal fonte de motivação da participante para se tornar professora de inglês. A próxima narrativa, por sua vez, mostra como um depoimento inspirador de uma professora também influenciou a escolha por essa carreira de outra participante:

I had a class with the professor Leni Nobre de Oliveira. Today I cannot mention the words she told us that day, but I can still hear her voice talking about her story, feel her passion about being a teacher. That passion she had came instantaneously into the [bottom] of my heart. I really knew that I was in the right place, doing exactly the course I should do. ${ }^{21}$

A inspiração também veio da visão. Observamos em algumas narrativas sobre autoempoderamento e visão que o fascínio pelas culturas de língua inglesa levou alguns participantes a continuarem seus estudos e se tornarem professores de inglês. Um dos participantes, por exemplo, revela que ver a si mesmo como um usuário proficiente da língua permitiu que ele ensinasse seus colegas de classe. Quando ele viu o papel que o inglês desempenhava em sua vida, a escolha por uma carreira de ensino de línguas foi feita de forma natural:

My choice to become a teacher was not based only on the fact that I would help people communicate through the language. But also because I could, somehow, become a role model for those who faced the same challenges I did, by showing them that even though they felt hopeless, useless, uninteresting or out casted, they also had their value, their qualities and talents, and that the world needs their light to become a place of acceptance and love. ${ }^{22}$

\footnotetext{
${ }^{20}$ Quando eu era criança, eu decidi ser professor de inglês. Minha mãe era babá e ela viajava por todo o mundo, apesar de não entender bem essa íngua, ela sempre [dizia]: "O inglês é muito importante e se você quer ter um bom emprego, você deve saber [essa língua].” Eu me tornei ciente da importância da língua inglesa e, por isso, comecei a estudar inglês num [conhecido] Instituto em outra cidade.

${ }^{21}$ Tive uma aula com a professora Leni Nobre de Oliveira. Hoje não consigo mencionar as palavras que ela nos disse naquele dia, mas ainda posso ouvir sua voz falando sobre sua história, sentir sua paixão por ser professora. Essa paixão que ela tinha veio instantaneamente ao [fundo] do meu coração. Eu realmente sabia que eu estava no lugar certo, fazendo exatamente o curso que eu deveria fazer.

22 Minha escolha por me tornar um professor não se baseou apenas no fato de que eu ajudaria as pessoas a se comunicarem através da linguagem. Mas também porque eu poderia, de alguma forma, me tornar um modelo para
} 
Esse participante, então, acredita que é possível ser um modelo para seus alunos, mostrando a eles, de maneira visual, ainda que metaforicamente, suas qualidades e seus talentos para que eles não se sintam desesperançosos, desinteressantes, inúteis ou excluídos.

Outra referência à visão foi oferecida no seguinte excerto, em que a participante se sentiu empoderada ao aprender inglês, mas tornou-se ainda mais confiante em seu futuro caminho profissional depois de frequentar um programa de graduação de estudos de inglês:

I have [been] studying English for five years and since then it has changed my life completely. I am from a small village in a rural zone in [the] North of Minas Gerais, but since the age of $17 \mathrm{I}$ left home and tried to look for a better future, without knowing what a better future was. I always wanted to speak English but I never imagined being a teacher. [...] The changes I mentioned before are not in [relation] to money or "status", but mostly personal. My [undergraduate course] permitted me to see the other people and the world differently. It opened my mind and I could see many points of view and my point of view, [which] was the most important..$^{23}$

O excerto acima mostra claramente como aprender inglês permitiu que a participante visse a si mesma e ao mundo de forma distinta. Outra narrativa que forneceu um insight relevante sobre a relação entre visão e a escolha de se tornar professora de inglês vem de uma participante negra. Depois de afirmar que ela se sentia intrigada por se ver como uma pessoa muito diferente dos outros alunos do instituto de línguas que frequentava, a participante decidiu se tornar uma professora para mostrar a si mesma e aos outros que o conhecimento é uma poderosa ferramenta de autoaceitação, confiança e respeito:

I always felt like I had to straight down my hair to have a better status as a student. Maybe it doesn't make sense for you, but my self-esteem is directly related to my studies and empowerment as a black woman. Since I have to prove every day for all my students, my colleagues, my co-workers and bosses that I could learn, speak and teach English and each day I have the [certainty] that I have chosen the right way, I mean, I have chosen the education area to show my students that they can reach any position they want to. I want to present them their rights and allow them to have a critical and politicized identity not only for the black ones, but also for that ones who have to run and fight for their own rights to have a better education. ${ }^{24}$

aqueles que enfrentaram os mesmos desafios que eu, mostrando-lhes que, apesar de sentirem-se desesperados, inúteis, desinteressados ou excluídos, também tinham seu valor, suas qualidades e talentos, e que o mundo precisa de sua luz para se tornar um lugar de aceitação e amor.

${ }^{23}$ Eu estudo inglês há cinco anos e desde então isso mudou minha vida completamente. Eu venho de uma pequena vila em uma zona rural no norte de Minas Gerais, mas desde os 17 anos saí de casa e tentei procurar um futuro melhor, sem saber o que era um futuro melhor. Sempre quis falar inglês, mas nunca imaginei ser professora. [...] As mudanças que mencionei antes não estão relacionadas ao dinheiro ou a "status", mas [são] principalmente pessoais. Meu [curso de graduação] me permitiu ver as outras pessoas e o mundo de maneira diferente. Isso abriu minha mente e pude ver muitos pontos de vista e meu ponto de vista, [o que] foi mais importante.

${ }^{24}$ Eu sempre senti como se eu tivesse que alisar meus cabelos para ter um melhor status como estudante. Talvez não faça sentido para você, mas minha autoestima está diretamente relacionada aos meus estudos e empoderamento como mulher negra. Como eu tenho que provar todos os dias para todos os meus alunos, meus colegas, meus colegas de trabalho e chefes que eu posso aprender, falar e ensinar inglês e cada dia tenho a certeza de que escolhi o caminho certo, quero dizer, escolhi a área de educação para mostrar aos meus alunos que podem chegar a qualquer posição que desejem. Quero apresentar-lhes os seus direitos e permitir-lhes ter uma identidade crítica e politizada, não só para os negros, mas também para aqueles que têm que correr e lutar por seus próprios direitos de ter uma educação melhor. 
As narrativas discutidas nessas duas seções fornecem apenas uma breve noção das muitas possibilidades de relacionarmos as experiências de aprendizagem de línguas aos sentidos do corpo humano, como propôs Pennycook (2015), e às identidades imaginadas dos alunos como futuros professores de inglês. Em suma, observamos como as experiências envolvendo sentidos despertaram não apenas oportunidades para o crescimento pessoal, mas também o desejo de proporcionar aos outros indivíduos as mesmas possibilidades de empoderamento, agência e senso de pertencimento a esse novo mundo, cheio de segredos e experiências ainda a serem vividas.

\section{REFLEXÕES FINAIS}

Como discutimos na introdução deste texto, as narrativas têm um papel penetrante na experiência humana. Acreditamos que o mesmo pode ser dito em relação às experiências sobre ensino e aprendizagem de línguas. A simples contagem das narrativas relacionadas aos cinco sentidos mostrou, como já apontado, que alguns sentidos surgem de maneira predominante nas narrativas dos participantes, especificamente os sentidos da audição e da visão, o que pode estar relacionado ao fato de que esses sentidos são aqueles mais diretamente relacionados às habilidades de compreensão oral e de leitura, vistas como habilidades básicas no processo de aprendizagem de uma língua estrangeira.

Embora se possa dizer que "narrativas e histórias fornecem apenas uma visão fragmentada" (KALAJA, MENEZES, BARCELOS, 2008, p. 232) das experiências humanas, a análise das narrativas geradas neste estudo oferece insights notáveis sobre como o contato com a língua inglesa pode funcionar como uma potente ferramenta para o empoderamento pessoal dos participantes. Foi possível notar que suas memórias relacionadas aos sentidos dentro do ambiente de aprendizagem de línguas, em certa medida, levaram a relatos não intencionais relacionando seu processo de aprendizagem de inglês com agência social, participação e senso de pertencimento.

Além do empoderamento pessoal, também pudemos perceber - direta ou indiretamente a conexão entre algumas narrativas e o eventual desejo dos participantes de se tornarem professores de inglês. Por meio de experiências que vão desde a vontade de escapar do preconceito até se verem de uma maneira diferente, bem como histórias envolvendo sua realização pessoal, tradições familiares e desejo de fazer a diferença no mundo, foi possível entender o papel do inglês nas vidas desses participantes, bem como a porta que o inglês abriu para alguns deles em relação à sua vida profissional e acadêmica.

Dado que hoje em dia vivemos em um mundo globalizado em que muitas pessoas têm acesso ilimitado a todo tipo de informação, pode-se entender que é necessário oferecer aos nossos alunos e professores em formação o maior número possível de oportunidades para melhorar o conhecimento do inglês por meio de atividades que promovam seu empoderamento pessoal, reforcem sua identidade e atentem ao seu senso de pertencimento. Por meio da ativação de seus sentidos, nós, como professores e formadores de professores, podemos criar espaços para alunos e professores em formação se sentirem parte de uma nova realidade e usarem o poder do conhecimento e das experiências para conquistar seu lugar no mundo.

\section{REFERÊNCIAS}

ADICHIE, C. N. The danger of a single story. [vídeo] Ted Talks 2009. Disponível em https://www.ted.com/talks/chimamanda adichie the danger of a single story?\#t-5053.

Acesso em: 19 out. 2009.

AHMED, S.; HAN, Z. Models of reading. In: LIONTAS, J. I. (Ed.). The TESOL encyclopedia of English language teaching. Singapore: Singapore, 2018. p. 2153-2159. 
AJAYI, L. Teaching/developing vocabulary using graphic organizers and modeling. In: LIONTAS, J. I. (Ed.). The TESOL encyclopedia of English language teaching. Singapore: Singapore, 2018. p. 3186-3197.

BARCELOS, A. M. F. Learning English: students' beliefs and experiences in Brazil. In: KALAJA, P.; MENEZES, V.; BARCELOS, A. M. F. (Orgs.). Narratives of learning and teaching EFL. Basingstoke, UK: Palgrave/MacMillan, 2008. p. 35-48.

BAILEY, K. M. et al. The language learner's autobiography: examining the "apprenticeship of observation". In: FREEMAN, D.; RICHARDS, J. C. (Eds.). Teacher learning in language teaching. New York: Cambridge University Press, 1996. p. 11-29.

BLAKE, R. W.; HAINES, S. Becoming a teacher: using narratives to develop a professional stance of teaching science. In: MATTOS, A. M. A. (Ed.). Narratives on teaching and teacher education: an international perspective. New York: Palgrave/MacMillan, 2009a. p. 47-76.

BRUNER, J. Actual minds, possible worlds. Cambridge, MA: Harvard University Press, 1986.

BRUNER, J. Making stories: law, literature, life. Cambridge, Mass: Harvard University Press: 2002. CASANAVE, C. P.; SCHECTER, S. R. On becoming a language educator: personal essays on professional development. Mahwah, NJ: Lawrence Erlbaum Associates, 1997.

CLANDININ, D. J.; CONNELLY, F. M. Narrative inquiry: experience and story in qualitative research. San Francisco: Jossey-Bass, 2000.

CLANDININ, D. J. et al. Places of practice: learning to think narratively. Narrative Works: issues, investigations \& interventions, v. 5, n. 1, p. 22-39, 2015.

CONNELLY, F. M.; CLANDININ, D. J. Stories of experience and narrative inquiry. Educational Researcher, v. 19, n. 5, p. 2-14, 1990.

DUBOC, A. P. M. Teaching with an attitude: finding ways to the conundrum of a postmodern curriculum. Creative Education, v. 4, n. 12B, p. 58-65, 2013. Disponível em: http://www.scirp.org/journal/PaperInformation.aspx?PaperID=41465\#.VX8 yflViko. Acesso em: 06 jan., 2014.

FELDER, R. M.; HENRIQUES, E. R. Learning and teaching styles in foreign and second

language education. Foreign Language Annals, v. 28, n. 1, p. 21-31, 1995. D.O.I.:

https://doi.org/10.1111/j.1944-9720.1995.tb00767.x

FREEMAN, D. Redefining the relationship between research and what teachers know. In: BAILEY, K.; NUNAN, D. Voices from the language classroom. New York: Cambridge University Press, 1996. p. 88-115.

GONÇALVES, S. Internacionalização em casa: a experiência da ESEC. Exedra, n. 1, p. 139-166, 2009. Disponível em: https://dialnet.unirioja.es/descarga/articulo/3398339.pdf. Acesso em: 21 out., 2018.

GRELLET, F. Developing reading skills. New York: Cambridge University Press, 1995.

HELLMAN, A. B. Teaching tired vocabulary. In: LIONTAS, J. I. (Ed.). The TESOL encyclopedia of English language teaching. Singapore: Singapore, 2018. p. 3364-3373.

JACOBS, G. M.; SHEGAR, C. Reading as a social process. In: LIONTAS, J. I. (Ed.). The TESOL encyclopedia of English language teaching. Singapore: Singapore, 2018. p. 2196-2201.

KALAJA, P.; MENEZES, V.; BARCELOS, A. M. F. (Orgs.). Narratives of learning and teaching EFL. Basingstoke, UK: Palgrave/MacMillan, 2008.

KRASHEN, S.; RENANDYA, W.; MASON, B.; BOSE, P. Paths to Competence in Listening Comprehension. Beyond Words, v. 6, n. 1, p. 1-3, May 2018.

MATTOS, A. M. A. (Ed.). Narratives on teaching and teacher education: an international perspective. New York: Palgrave/MacMillan, 2009a.

MATTOS, A. M. A. A tail of hope: preservice teachers' stories of expectation toward the profession. In: MATTOS, A. M. A. (Ed.). Narratives on teaching and teacher education: an international perspective. New York: Palgrave/MacMillan, 2009b. p. 203-215. 
MATTOS, A. M. A. Understanding classroom experiences: listening to stories in order to tell stories. In: MATTOS, A. M. A. (Ed.). Narratives on teaching and teacher education: an international perspective. New York: Palgrave/MacMillan, 2009c. p. 31-45.

MATTOS, A. M. A. Educating language teachers for social justice teaching. Interfaces BrasilCanada, v. 14, n. 2, p. 125-151, 2014. Disponível em: https://periodicos.ufpel.edu.br/ojs2/index.php/interfaces/article/view/6738/4644. Acesso em: 24 set., 2016.

MAUÉS, O. C.; BASTOS, R. S. Políticas de internacionalização da Educação Superior: o contexto brasileiro. Educação, v. 40, n. 3, p. 333-342, 2017. Disponível em http://www.redalyc.org/articulo.oa?id=84854915008. Acesso em: 21 out., 2018.

NUTTAL, C. Teaching reading skills in a foreign language. Oxford: Macmillan Heinemann, 2000.

PAIVA, V. L. M. O. Autonomia e complexidade: uma análise de narrativas de aprendizagem. In: FREIRE, M. M.; ABRAHÃO, M. H. V.; BARCELOS, A. M. F. (Orgs.). Linguística Aplicada e contemporaneidade. Campinas e São Paulo: Pontes e ALAB, 2005. p. 135-153.

PAIVA, V. L. M. O. Memórias de aprendizagem de professores de língua inglesa. Contexturas, v. 9, p. 63-78, 2006. Disponível em: http://www.apliesp.org.br/site-resumo item edicao?id=98. Acesso em: 25 jul., 2016.

PENNYCOOK, A. English from below. In: CONGRESSO BRASILEIRO DE LINGUÍSTICA APLICADA, 11., 2015, Campo Grande-MS. Minicurso... Campo Grande-MS: Associação de Linguística Aplicada do Brasil/Universidade Estadual de Mato Grosso do Sul, 14/07/2015.

PINNEGAR, S.; DAYNES, J. G. Locating narrative inquiry historically. In: CLANDININ, D. J. (Ed.). Handbook of narrative inquiry: mapping a methodology. Thousand Oaks, CA: Sage Publications, 2007.

PRESTON, A. et al. Can a kitchen teach languages? Linking theory and practice in the design of context-aware language learning environments. Smart Learning Environments, v. 2, n. 9, p. 2-19, 2015. D.O.I.: $10.1186 /$ s40561-015-0016-9

RAMOS, M. Y. Internacionalização da pós-graduação no Brasil: lógica e mecanismos. Educaşão \& Pesquisa, São Paulo, v. 44, p. 1-22, 2018. D.O.I.: http://dx.doi.org/10.1590/s15179702201706161579.

ROST, M. Listening. In: CARTER, R.; NUNAN, D. The Cambridge guide to teaching English to speakers of other languages. Cambridge: Cambridge University Press, 2001. p. 7-13.

SADEGHI, K. Comprehension processes. In: LIONTAS, J. I. (Ed.). The TESOL encyclopedia of English language teaching. Singapore: Singapore, 2018. p. 2058-2063.

SIEGEL, J. Researching listening through action research. In: LIONTAS, J. I. (Ed.). The TESOL encyclopedia of English language teaching. Singapore: Singapore, 2018. p. 1473-1479.

VANDERGRIFT, L.; CROSS, J. Cognitive listening strategies. In: LIONTAS, J. I. (Ed.). The TESOL encyclopedia of English language teaching. Singapore: Singapore, 2018. p. 1287-1292.

WALLACE, C. Reading. In: CARTER, R.; NUNAN, D. The Cambridge guide to teaching English to speakers of other languages. Cambridge: Cambridge University Press, 2001. p. 21-27.

Submetido em $27 / 10 / 2018$

Aceito em 11/12/2018

Publicado em 13/02/2019 